\title{
Using Lexical Chunks Theory to Improve English Reading Ability
}

\author{
Shuhong Ling
}

Teaching and Research Institute of Foreign Languages, Bohai University, Jinzhou, 121013, China

1017651635@qq.com

Keywords: lexical chunks theory; English language teaching; reading ability; ways

\begin{abstract}
When students do English reading, they often spend a lot of time identifying words, which reducing reading speed and affecting the understanding of the whole chapter. Lexical chunks, as a whole unit stored in human brain, which can reduce the time for brain processing information, can help automatically identify and extract, and can improve the fluency and accuracy of language expression. The theory of lexical chunks provides a new idea for English reading teaching. Based on functional classification of lexical chunks, this paper analyzes the effect of lexical chunks on English learning and English reading teaching, and puts forward ways to improve English reading ability by using lexical chunks theory. The specific ways include: cultivate the consciousness of lexical chunks, the use of extracurricular resources to expand lexical chunks learning channels, in the context of reading to learn lexical chunks and use lexical chunks to analysis chapter structure.
\end{abstract}

\section{Introduction}

Reading, as an important way of language input, occupies an important position in English teaching. Improving students' English reading ability is not only the purpose of English learning, the means of learning English well, but also the way to test students' English knowledge, cultural knowledge, thinking ability, comprehensive ability to deal with information, and it is the only way for students to increase cultural knowledge, expand cultural vision, enhance literary accomplishment, improve self-learning ability. When students do English reading, they usually need to spend a lot of time identifying words, reducing reading speed, decentralizing the understanding and discourse processing capability, affecting the understanding of the whole chapter. At present, the popular English reading teaching mode and the psychological language reading mode emphasize the role of grammatical knowledge in the understanding of article. The bottom-up mode advocates the meaning of gradual construction from the word to the chapter, but the interactive mode emphasizes the diversification of information processing. These reading models can not get rid of relying on the grammar and words.

Lexical chunks, which has relatively fixed structure, has meaning with more stable combination of words, covering phrase, fixed collocation and idioms, etc. As the whole processing stored in memory, the use of lexical chunks leaves out language computing resources and response time the grammar rules temporarily generated, which can help achieve different pragmatic functions. Lexical chunks can be stored as a whole unit in human brain, use it to reduce the time for brain dealing with information, help automatically identify and extract, and improve the fluency and accuracy of language expression. Due to the limited vocabulary and the negative transfer of native language, students often have a certain sense of fear in English expression, which is not conducive to English learning. Compared with the word, lexical chunks is easier to remember, lexical chunks learning and mastering can help students to expand vocabulary, increase language input, help accelerate the language output speed, improve language expressive ability. As an effective way of learning, lexical chunks learning strategy provides a new idea for foreign language teaching. This paper is based on the theory of lexical chunks to improve the ability of English reading ability, so as to improve the teaching level of English reading.

\section{Functional Classification on Lexical Chunks}

The function of lexical chunks is studied from different points and classified functions, of which the 
most representative is Nattinger \& DeCarrico and Moon [1].

Nattinger \& DeCarrico combines lexical chunks with actual English teaching. The function of lexical chunks is divided into three categories in specific context: first, social interaction function, the description of social relation from social interaction initiators, including functional significance lexical chunks related to conversation maintenance and conversation purpose. Conversation maintenance shows how the conversation starts, develops and ends. For example, "excuse me" means call, "what's wrong with you" means respond call, "where is she from?" means give rise to topic, "let us move on to the next topic" means the topic conversion, "see you" means leave. The purpose of conversation is refer to the purpose of conversation initiated by the speaker. For example, "can you ...?" means request, "May I help?" means offer help, "I'm sorry to turn you down" means refuse. Second, topic needs function, including the lexical chunks for speaker to ask questions or answer in daily conversations. Such as: "I don't like" means favor, "Today's weather is awful" means the weather condition, "in the front of" means location, "How many is?" means inquiry numbers. Third, textual cohesion function, contains lexical chunks about discourse structure and meaning. For example, "in spite of" means logical connection; "for instance" means give an example; "in my opinion" means evaluation; "in summary" means summary.

Moon divides the function of the lexical chunks into five categories according to the effect of lexical chunks on discourse content and structure: first, information function, indicating that lexical chunks have the function of stating topic and transmitting information. For example, by means of, in the running, etc. Second, evaluation function, express speaker's evaluation and attitude. For example, it's an ill wind, a pain in the neck, etc. Third, situation function, is closely related to language background and contains response to the situation. For example, excuse me, long time no see, so long, etc. Fourth, preach function, contains not only the real evaluation, but also advice and expression request. For example, as you know what I mean, I kid you not, etc. Fifth, organization function. In addition to being able to organize the discourse structure, it can also sign the discourse structure. For example, furthermore, by the way, for instance, etc.

\section{Role of Lexical Chunks for English Study}

Lexical chunks plays an important role in English learning, highlighting in the following four aspects:

(1) Lexical chunks, is conducive to reduce the brain's memory burden. The scope of lexical chunks is much larger than vocabulary, and also combines the advantages of grammar, semantics and context, the form is relatively fixed, can be identified and extracted as a whole, and is conducive to memory. Marking and understanding lexical chunks is also a meaningful learning activity, relatively speaking, memorizing lexical chunks is easier than vocabulary, so it can reduce the language learner's brain memory burden.

(2) Lexical chunks can improve the students' consciousness of using lexical chunks to enhance the accuracy and fluency of language expression. Learner can extract and use the lexical chunks in its entirety, do not need to carefully consider the rules of composing the words and phrases again, do not need to consider whether the sentence structure is correct, can accelerate the language processing speed and reduce the language error, and enhance the language expression accuracy and fluency.

(3) Lexical chunks can help students reduce the impact of the negative transfer of native language. In the process of second language learning, due to the negative transfer of native language, students' language expression thinking will be restricted, the organization language is prone to grammar and vocabulary collocation errors. Lexical chunks is the high frequency of multi-word units in real language communication, in addition to high frequency, the form is relatively fixed. Expression can be directly extracted to help students overcome the negative impact of negative transfer of native language.

(4) Lexical chunks is conducive to establish students' confidence, strengthen students' learning motivation. Lexical chunks is more in line with the basic law of memory, lexical chunks stored in the brain, when language learners need, no need to analyze the phrase structure is correct or not. 
This fast language processing speed, can reduce the burden on students, reduce the anxiety of language expression, stimulate students' learning motivation, and enhance learning self-confidence.

\section{Role of Lexical Chunks for English Reading Teaching}

The effect of lexical chunks on English reading teaching is mainly embodied in the following three aspects:

(1) Lexical chunks constitutes the unit of English reading. The basic unit of English language is composed of lexical chunks of high frequency and varying degrees. Faster readers in English reading, long sentence is usually divided into a number of sense-groups composed of several words, which is prefabricated fixed expression. Lexical chunks, as a unit of meaning, in the form of overall storage and extraction, can help readers in English reading, can transfer the attention from single vocabulary and grammar to overall meaning of the unit, focused on the hierarchical structure of the text, and improve the degree of reading comprehension.

(2) Lexical chunks improve the speed of English reading. Reading speed refers to the level of understanding meeting certain requirements, read article's speed, usually expressed in words per minute. Nuttall points out that in order to improve the speed of English reading, it is necessary to use chunk reading with the meaning, rather than read word by word. This fully shows that the lexical chunks is the ideal reading unit, the use of word block reading, can not only improve the reading speed, but also expand the visual breadth. Many scholars have shown that lexical chunks is the ideal English reading unit, and has a significant effect for improving the reading speed.

(3) Lexical chunks promote discourse comprehension of English reading. Lexical chunks contain a lot of semantic and contextual information, and the mastery of these words plays a key role in understanding the content for reader. The macroscopic and micro - organizational functions of the lexical chunks make it possible to keep students understanding the logical relationship between discourse and intercourse. Different types of genres have different stylistic identification chunks, analyze the stylistic features of different words, understand the structure of various genres and the mode of text, improve the literary consciousness of English reading, and help to grasp the overall structure and direction of the article.

\section{Ways of Using Lexical Chunks Theory to Improve English Reading Ability}

The way of using lexical chunks theory to improve the English reading ability, mainly summarized as follows:

(1) Cultivate lexical chunks consciousness. The fluency of students using language, not depending on how much grammar rules are stored in the brain, but how many prefabricated words. Therefore, daily English teach students to cultivate lexical chunks consciousness and lexical chunks sensitivity, help students identify the lexical chunks in the reading process, and consciously contact the lexical chunks. Specific strategies include three aspects[2]: first, teaching students to guide and understand the lexical chunks. In teaching practice, students are guided to strengthen the ability to capture and perceive the lexical chunk, abandon the traditional way of explaining the vocabulary, start from the whole article, guide the students to grasp the article's purpose, chapter structure and the lexical chunks analysis ability. Second, provide students with chances of lexical chunks output. make full use of the classroom time to guide students to repeatedly refining and use, give students enough opportunity to feel and understand the lexical chunks, experience the use of words in different scenarios, enhance the practical use of confidence and enthusiasm. Third, encourage students to recite the lexical chunks after class. Combined with the classroom learning content, increase the lexical chunks and similar statements in collection and collation, after school recite the lexical chunks, continue to accumulate, develop good learning habits, and promote students' English reading ability to improve.

(2) Use extracurricular resource to expand lexical chunks learning channels. Extracurricular reading is an effective way to gain information, enhance language sense, expand vocabulary, and improve your English. Extracurricular reading is conducive to cultivating students' independent 
reading methods and learning habits, so that students have more time to contact English, stimulate students' interest in English learning and clear language learning motivation, help students improve reading comprehension skills and cultivate good extracurricular reading habits. Through extensive extracurricular reading, improve learning English interest, cultivate information and handle information. Extracurricular reading is also a supplement and extension of class reading, diverse and rich in content, providing students with a real language environment, helping students to consolidate their existing language knowledge and cultivate independent reading ability. It is an indispensable part of English learning. Extracurricular resources include English magazines, newspapers and network resources. Under the guidance of lexical chunks theory, English extracurricular reading needs to pay attention to two aspects[3]: First, through contact with a large number of words, strengthen the understanding of lexical chunks, and cultivate the ability to identify lexical chunks; second, consciously accumulate lexical chunks, expand the vocabulary, and constantly enrich the language material, improve the vocabulary matching ability and language organization.

(3) Learn lexical chunks in the context of reading. Reading is based on a specific contextual reading, calling the brain's existing knowledge reserves and cultural knowledge, accompanied by certain mental and emotional activities, the external language reproduce the context of "character or affair" process[4]. Comprehensively and profoundly understand the context, not only help understand the content of the article, but also help in the context of learning vocabulary, consolidate the grammar, understand the rhetoric and chapter structure, achieve understanding, appreciation and evaluation purposes. Misunderstanding or misinterpretation of the context, it can not correctly understand the meaning of the text and the author's intention. Therefore, context comprehension becomes the key to improve English reading ability. The necessary topic function and discourse strategy function can help students to better understand the subjective and overall structure of the article. Teachers should focus on the choice of strong and high frequency of the lexical chunks to help students understand the meaning and usage of the lexical chunks, so that students can classify the lexical chunks, through group to discuss the meaning and usage of the lexical chunks. In the context of article to understand, you can also choose to close the students life examples, promote students to understand and remember. Help students understand the meaning of the lexical chunks according to the context, and better understanding of the content of article.

(4) Use lexical chunks to analysis chapter structure. The discourse structure and the reading comprehension are intrinsically connected. When reading can not focus on words and sentences, the discourse theory should be applied to English reading, starting from the overall structure, the discourse as the basic unit, based on the overall situation, discourse consciousness and discourse ability. With the help of discourse structure knowledge, grasp the discourse genre, chapter type, chapter mode and chapter strategy, reading materials comprehensive and in-depth understanding, and achieve communication with the author of the text. Reading the teaching of the "lexical chunks teaching method", lexical chunks as a whole organization of teaching, let students turn their attention from the word to lexical chunks structure, use lexical chunks to analysis the chapter structure, so the structure of the article clear, from the overall grasp of the context[5]. In the process of teaching, teachers can use lexical chunks to analyze the structure of article, understand the logical relationship between the article and writing intention; and then let the students understand the role of lexical chunks in the discourse, with the help of lexical chunks analysis of the article. Students master these fixed and semi-fixed words, and the prefabricated structure of these languages organically combine to form cohesive coherent text, improve discourse understanding and generate perceptual knowledge, thereby enhancing the level of reading comprehension.

\section{Conclusion}

Improve the ability of English reading, not only cultivate students' thinking ability, analyze ability and understand ability, but also cultivate students' listening and writing ability to lay foundation, and effectively improve the students' ability to use language. The theory of lexical chunks provides a new idea for English reading teaching. The lexical chunks are neither fixed as idioms nor as 
difficult to understand for the lack of predictability. On the contrary, lexical chunks in a relatively fixed case can be innovative, can be regarded as a good way to learn. In English reading teaching, teachers and students should give enough attention. For teachers, teachers to guide students to classify lexical chunks to help students accumulate and remember, in the study of infiltration word block definition, classification, function and other related knowledge. Teachers in the real reading discourse, use lexical chunks method to analysis and reading, give examples to students, then students gradually learn to use the method. For students, we must set up the sense of lexical chunks, in the daily learning activities, proactively find lexical chunks and learn lexical chunks, gradually accustomed to reading with lexical chunks, can use lexical chunks analysis discourse, and achieve the purpose to improve English reading ability.

\section{Acknowledgement}

This work is supported by social science fund project of Liaoning province: Research on training strategies for English reading and writing ability based on lexical chunks theory (L15BYY009).

\section{References}

[1] W. L. Zhang, "The Application of the Lexical Chunk to the Teaching of English Reading in Junior High school," Master's degree of Chongqing Normal University, 2016.

[2] L. H. Sun, "Strategies for cultivating students' awareness of lexical chunks in English teaching in higher vocational colleges," Time Education, vol. 12, no. 2, pp. 115-115, 2015.

[3] Paper nets, "An analysis of English reading teaching strategies in senior high school based on lexical chunks theory," http://www.xzbu.com/9/view-6229593.htm, 2017-4-19.

[4] N. Xie, G. Q. Liu, "The characteristics of context understanding and its implications for teaching in English reading," Journal of Shenyang Normal University (Social Science Edition), vol. 36, no. 6, pp. 148-150, 2012.

[5] J. L. Zhong, "Accumulate the word block effectively, Improve students' English reading ability," New Curriculum Research, vol. 12, no. 10, pp. 63-64, 2015.

[6] W. L. Zhu, "A Research on the Application of Lexical Chunks to English Extracurricular Reading in Senior High School," Master's degree of Fujian Normal University, 2016.

[7] J. Q. Fu, "The Application of the Lexical Chunks to English Reading Teaching in Senior High School," Master's degree of Fujian Normal University, 2016.

[8] H. Y. Hu, "The Application of the Theory of Lexical Chunks to English Teaching at Senior High Schools," Master's degree of East China Normal University, 2015.

[9] C. J. Xu, "Cultivation of college students' awareness of lexical chunks," Data of Culture and Education, vol. 42, no. 2, pp. 189-190, 2013. 